Research Article

\title{
Pressure Load Characteristics of Nonideal Explosives in a Simulation Cabin
}

\author{
Chuan-hao Wang ${ }^{D}$, Shu-shan Wang ${ }^{\mathbb{D}}$, and Jing-xiao Zhang $\mathbb{1}$ \\ State Key Laboratory of Explosion Science and Technology, Beijing Institute of Technology, Beijing 100081, China \\ Correspondence should be addressed to Shu-shan Wang; wangshushan@bit.edu.cn
}

Received 13 May 2019; Accepted 29 July 2019; Published 24 September 2019

Academic Editor: Evgeny Petrov

Copyright (C) 2019 Chuan-hao Wang et al. This is an open access article distributed under the Creative Commons Attribution License, which permits unrestricted use, distribution, and reproduction in any medium, provided the original work is properly cited.

\begin{abstract}
In this study, an aluminum-containing charge was exploded in an enclosed simulation cabin to explore the characteristics of two types of damaging pressure loads formed by internal explosions: the first incident shock wave and the quasistatic pressure. A highfrequency piezoelectric sensor was used to measure the first incident shock wave and a low-frequency piezoresistive sensor was used to measure the quasistatic pressure. After obtaining effective experimental data, the experimental results were compared with the values obtained by the classical calculation model. The results show that the pressure loads generated by the internal explosions from the ideal explosive and the aluminum-containing explosive share similar load characteristics, given the same mass and benchmark explosive. The difference between the two explosives primarily lies in the amplitude of the load parameters. The aluminum-containing explosive has lower first incident shock wave and higher quasistatic pressure than that of the ideal explosive. For the peak overpressure of the first incident shock wave, the explosion shock wave load parameters of the aluminumcontaining explosive, which are calculated based on the explosion heat theory, are higher than the measured values. The peak quasistatic overpressure is directly related to the total energy released by the explosion; however, they are hardly correlated with the reaction process. Therefore, the aerobic postcombustion reaction of the aluminum-containing explosive does not affect the analysis and calculation of the peak quasistatic overpressure. As a result, given the heat value of the explosive, the peak quasistatic overpressure of the explosive can accurately be obtained.
\end{abstract}

\section{Introduction}

If an explosion occurs in a limited space, two types of typical pressure loads will be generated: shock wave and quasistatic pressure. Restricted by boundary conditions, the time histories of pressure loads caused by an internal explosion are much more complicated than those generated by an external explosion, and more serious damage will often occur $[1,2]$. The shock wave is continuously reflected inside the confined space and superimposed at the corners, causing plastic deformation and local tearing of the structure. The first shock wave is decisive; the quasistatic pressure is considered a decisive factor that triggers structural disintegration and overall destruction based on structural and local damage. Therefore, the first incident shock wave and quasistatic pressure are important factors for analyzing and evaluating the damage effect.
Studies on the pressure load characteristics of explosions in enclosed cabins were commenced during World War II [3]. It was originally believed that the reflected shock wave was the main damage load. In the 1960s, the quasistatic pressure load began to receive attention. Relevant books [4-6], reports [7-10], and manuals [11-13] mainly covered the relationships between the two types of pressure loads and the mass and position of the explosive, the volume of the confined space, and the area of pressure relief. The calculation model of the two load parameters within a specific scope of application and the interplay between the pressure loads and the structure were also reviewed. These research findings have achieved the prediction and evaluation of pressure loads caused by internal explosions. In terms of mechanism research, studies on the reflected shock wave mainly included the theoretical calculation of multiple reflected shock waves [14-16] as well as the interaction 
between the shock wave and a confined space [17-20]. Studies on quasistatic pressure mainly covered the calculation of the load parameters of the quasistatic pressure [21-23], the effect of postcombustion on the quasistatic pressure [24-27], and the effect of the shape and structure of the pressure relief hole on the quasistatic pressure [28-32]. With the advent of thermobaric explosives, nonideal explosives have recently been used in internal explosions in confined spaces. Unlike ideal explosives, there is little research on the internal explosion pressure load of nonideal explosives [33, 34]. In addition, nonideal explosives tend to have more complicated internal explosion pressure load characteristics due to their complex reaction processes and energy release patterns. As the damage capacity of the internal explosion load increases, and with increasingly high requirements on the structural anti-internal explosion performance, it is important to study the pressure load characteristics of nonideal explosives in internal explosions. In this study, an explosion experiment was conducted in a simulation cabin. Two kinds of pressure sensors were used to simultaneously test the reflected shock wave and the quasistatic pressure. Based on theoretical analysis and calculation, this study aimed to explore the characteristics of pressure loads generated by the internal explosion of an aluminum-containing explosive.

\section{Pressure Load Characteristics of Explosion inside the Cabin}

When an explosion occurs in a limited space, the explosive will form a high-temperature and high-pressure detonation product as well as rapidly expand the compressed air to form an explosion shock wave in the air. After the explosion shock wave is separated from the explosive product-air interface, the product continues to expand and gradually mixes with the air compressed by the shock wave. Subsequently, the shock wave reaches the boundary of the finite space and is reflected, and the spatial Euler point exhibits a fluctuating process where the peak pressure is continuously attenuated [23]. The average value of such fluctuating pressure is called the quasistatic pressure. For an observation point on a solid wall, the quasistatic pressure starts from the moment the shock wave first arrives and reflects and continues until it reaches its peak when the detonation product is mixed with the original air. Due to the short time frame, the pressure drop caused by the existence of the pressure relief hole and the heat exchange between the gas and the solid walls can be ignored. The quasistatic pressure continues to decrease over time, and this decay process lasts for seconds.

The flow field pressure characteristics of an explosion in a cabin are revealed as the fluctuating pressure featuring constant reflection on the observation point at the bulkhead occurs, which can be decomposed into two types of damaging pressure loads: the first incident shock wave and the quasistatic pressure. The pressure loads can be analyzed and processed relatively independently. The load parameters of the first incident shock wave include the first peak overpressure, positive pressure action time, and specific impulse. The load parameters of the quasistatic pressure include the peak overpressure of the quasistatic pressure, pressure relief time, and specific impulse. The amplitude of the first incident shock wave is typically on an order of magnitude of $10 \mathrm{MPa}$, and the positive pressure action time is on an order of magnitude of milliseconds, which are typical high-frequency pressure signals. Hence, to test the first incident shock wave, the sensor should have a response frequency of hundreds of kilohertz, and the collector should have a sampling frequency in megahertz. The quasistatic pressure is usually on an order of magnitude of kilopascals, and the pressure relief time is on an order of magnitude of seconds. Moreover, since the quasistatic pressure is the average of the fluctuating pressure, the response frequency of the quasistatic pressure test sensor should be low (kilohertz) to ensure that the data are stable and that it is possible to obtain a smooth test curve.

\section{Explosion Experiment in the Simulation Cabin}

3.1. Experimental Charge. To study the pressure load characteristics of aluminum-containing explosives during internal explosions, two propellant grains with different formulas were prepared in the experiment. Formula 1 was made from cyclonite and paraffin; formula 2 was made from cyclonite, aluminum powder, and paraffin. Both the propellant grains were $40 \mathrm{~g}$. To ensure the successful detonation of the propellant grains, each grain was equipped with a small booster grain ( $5 \mathrm{~g} 8701$ explosive), and the $8^{\text {th }}$ electric detonator was used to detonate the grains. The detonation parameters of the two explosives were calculated by the commercial software EXPLO5 (OZM Research) for theoretical analysis and calculation. Table 1 shows the composition and theoretical detonation parameters of the experimental charge. With a high content of RDX, the formula 1 explosive will produce a higher detonation velocity and detonation pressure during the detonation reaction. The explosion heat indicates the heat released by the explosion of the explosive. The aluminum powder in the aluminum-containing explosive can lead to intense postcombustion reactions and release of energy, resulting in a higher explosion heat value than the formula 1 explosive.

Two propellant grains with different formulas were prepared using the same process. Figure 1 shows the two propellant grains, with the formula 1 explosive $(\phi 30 \mathrm{~mm} \times 35.5 \mathrm{~mm})$ on the right and the aluminum-containing formula 2 explosive $(\phi 30 \mathrm{~mm} \times 33.9 \mathrm{~mm})$ on the left. Three propellant grains were made using each formula; in total, there were six grains and six internal explosion experiments were carried out. Generally, the density of the prepared grains was approximately $95 \%$ of the theoretical density. The TNT equivalents of the explosives with different formulas were calculated based on the explosion heat theory [35]:

$$
W=m_{\mathrm{a}} Q_{\mathrm{a}}=m_{\mathrm{TNT}} Q_{\mathrm{TNT}},
$$

where $W$ is the total energy released by the explosive $(\mathrm{J}), m_{\mathrm{a}}$ is the mass of the actual explosive $(\mathrm{g}), m_{\mathrm{TNT}}$ is the TNT 
TABLE 1: Composition and theoretical detonation parameters of experimental charge.

\begin{tabular}{lccccc}
\hline Formula & Composition & Density $\left(\mathrm{g} / \mathrm{cm}^{3}\right)$ & Explosion heat $(\mathrm{J} / \mathrm{g})$ & Detonation velocity $(\mathrm{m} / \mathrm{s})$ & Detonation pressure $(\mathrm{GPa})$ \\
\hline 1 & RDX/Wax $(95 / 5)$ & 1.675 & 5428.47 & 8448.54 & 29.68 \\
2 & RDX/Al/Wax $(80 / 15 / 5)$ & 1.757 & 7330.93 & 8054.66 & 28.76 \\
\hline
\end{tabular}

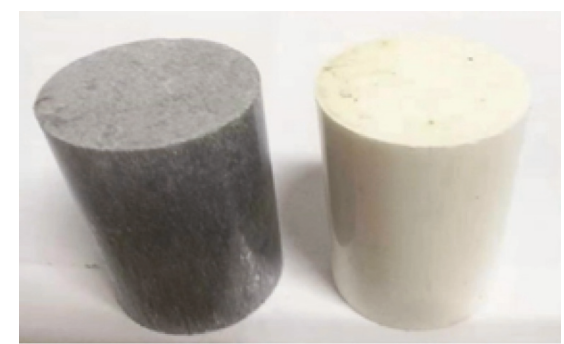

Figure 1: Experimental charge.

equivalent of the explosive ( $\mathrm{g}), \mathrm{Q}_{\mathrm{a}}$ is the theoretical explosion heat value of the actual explosive $(\mathrm{J} / \mathrm{g})$, and $Q_{\mathrm{TNT}}$ is the theoretical explosion value of the TNT explosive $(\mathrm{J} / \mathrm{g})$.

If the theoretical explosion heat value of the TNT explosive was $4184 \mathrm{~J} / \mathrm{g}$, the TNT equivalent of the formula 1 explosive was $52 \mathrm{~g}$, and the TNT equivalent of the formula 2 explosive was $70 \mathrm{~g}$.

3.2. Cabin Structure and Test Methods. Figure 2 shows the structure of the simulation cabin. The inner space was $600 \mathrm{~mm} \times 600 \mathrm{~mm} \times 600 \mathrm{~mm}$. Made of Q235 steel, the bulkhead was $16 \mathrm{~mm}$ thick. For the mass of the explosives used in this study, the cabin can be regarded as a rigid body structure. A circular hole with a diameter of $70 \mathrm{~mm}$ was drilled in the center of the top bulkhead for placing the charge. There were four test points on the simulation cabin, which were located at the center of each of the four bulkheads. High-frequency piezoelectric sensors were installed at test points 1 and 2 to test the first incident shock wave. The CY-YD-203T sensors produced by Sinocera Piezotronoics Inc. (Yangzhou, Jiangsu Province, China) were selected. Each sensor had a range $0-30 \mathrm{MPa}$, an output voltage of $0-5 \mathrm{~V}$, a working temperature of $-40^{\circ} \mathrm{C}$ to $150^{\circ} \mathrm{C}$, and a response frequency of $100 \mathrm{kHz}$. Low-frequency piezoresistive sensors were installed at test points 3 and 4 to test the quasistatic pressure. The CY-YZ-010 sensors produced by Sinocera Piezotronoics Inc. were selected. Each sensor had a range of $0-1 \mathrm{MPa}$, an output voltage of $0-5 \mathrm{~V}$, a working temperature of $-40^{\circ} \mathrm{C}$ to $85^{\circ} \mathrm{C}$, and a response frequency of $2 \mathrm{kHz}$.

Figure 3 shows the diagram of interior view of the experimental facility. The charge and gauges are at the same height. For the shock wave test point, the sensors were installed in the through-holes reserved on the bulkhead. There were tooling parts made from nylon between the bulkhead and the sensor. Characterized by elasticity and insulation, nylon can effectively block interference signals such as mechanical vibration, electrical signals, and stress waves. The sensor was installed in the nylon tooling parts, and there was an interference fit between the nylon sleeve and the through-hole on the bulkhead to ensure a tight

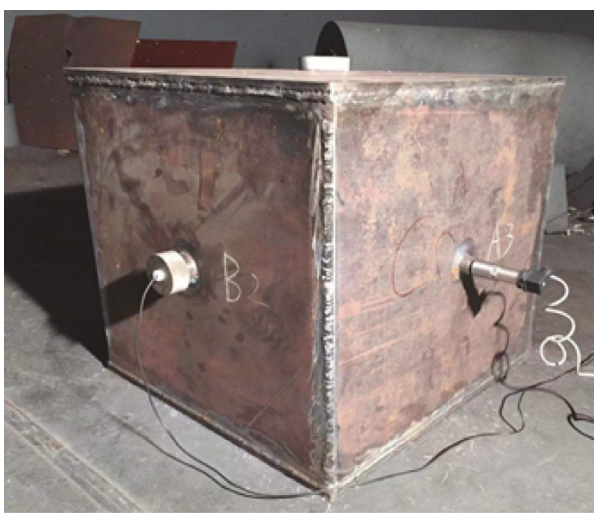

FIGURE 2: Structure of the simulation cabin.

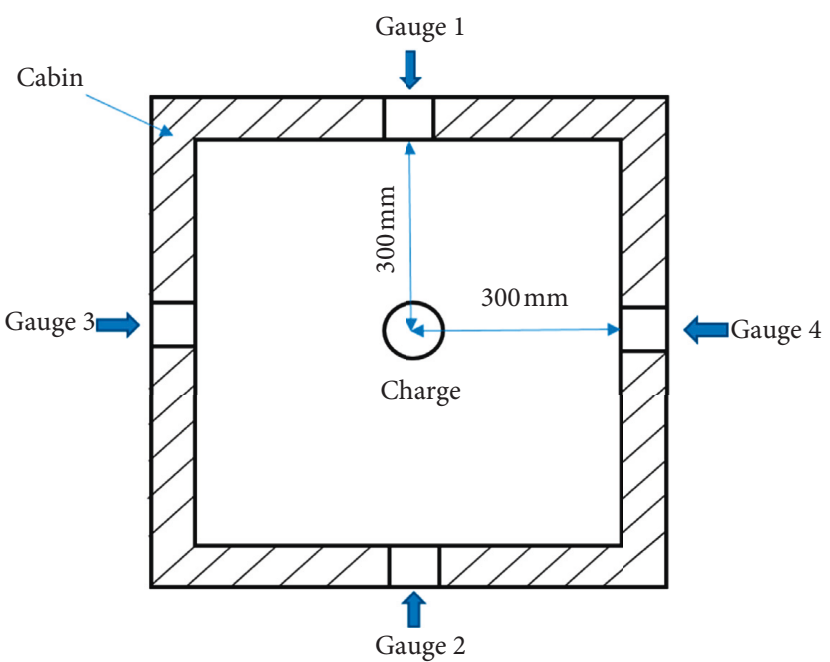

FIGURE 3: The diagram of interior view of the experimental facility.

installation. The pressure-sensitive surface of the sensor was flush with the inner side of the bulkhead, and the wires were fixed to prevent shaking. A metal buckle cap was used at the end of the nylon sleeve to compact the entire tooling part. As for the quasistatic pressure test points, nylon sleeves were also installed, and the tooling parts were screwed to the bulkhead to effectively block interference signals such as mechanical vibration, electrical signals, and stress waves.

Figure 4 displays the measurement system used in the experiment. An IDH446 data acquisition instrument (HBM, Suzhou, Jiangsu Province, China) was used for data acquisition. A YE5853 charge amplifier manufactured by Sinocera Piezotronoics was used as the charge amplifying device. The high-frequency piezoelectric sensor was connected to the charge amplifier. The sensitivity was set equal to that of the sensor. The amplification factor was three, the charge amplifier was connected to the data acquisition 


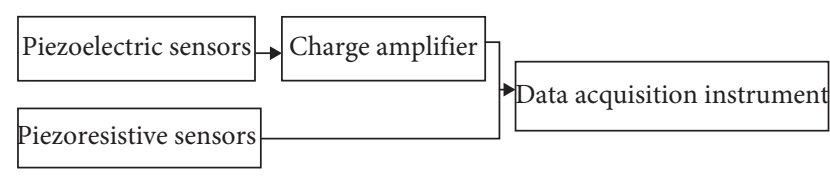

Figure 4: Measurement system used in the experiment.

instrument, and the sampling frequency of the two reflected shock wave signal channels was $10 \mathrm{MHz}$. The low-frequency piezoresistive sensor was directly connected to the data acquisition instrument, and the two quasistatic pressure signal channels had a sampling frequency of $10 \mathrm{kHz}$. After the explosive was detonated, when the first shock wave was transmitted to the high-frequency piezoelectric sensor, the four channels started collecting data simultaneously.

\section{Results}

In terms of the internal explosion pressure load parameters of the two explosives, experimental data were statistically calculated by deleting unreasonable data and averaging the effective data.

As shown in Figure 5, for the first incident shock wave received in the center of the bulkhead, the peak overpressure of formula 1 explosive was $26.65 \mathrm{MPa}$ and the positive pressure action time was $0.072 \mathrm{~ms}$. The formula 2 explosive had a peak overpressure of $19.23 \mathrm{MPa}$ and a positive pressure action time of $0.075 \mathrm{~ms}$. Given the same mass, the peak overpressure of the first incident shock wave of the formula 1 explosive was higher than that of the formula 2 explosive, but its positive pressure action time was slightly shorter than that of the formula 2 explosive. Most of the energy of the aluminum-containing explosive was released by the postcombustion reaction of the aluminum powder, and this energy did not act on the detonation wave front. Therefore, the peak overpressure of the shock wave of the aluminum-containing explosive was smaller than that of the ideal explosive. The positive pressure action time of the formula 2 explosive was longer than that of the formula 1 explosive because the postcombustion reaction of the aluminum-containing explosive endowed the shock wave positive pressure zone with more energy, which made the positive pressure last longer. The impulse-time curve of the first incident shock wave has been obtained by integral calculation from the curve in Figure 5, as shown in Figure 6.

It can be seen from Figure 7 that, for the quasistatic pressure received by the bulkhead, the peak overpressure of the formula 1 explosive was $0.53 \mathrm{MPa}$, and the positive pressure action time was $0.25 \mathrm{~s}$. The formula 2 explosive had a peak overpressure of $0.65 \mathrm{MPa}$ and a positive pressure action time of $0.26 \mathrm{~s}$. The formula 1 explosive reached the peak of quasistatic pressure slightly earlier than the formula 2 explosive. Due to the postcombustion reaction of the aluminum powder, the aluminum-containing explosive had a longer reaction time than the ideal explosive; thus, the quasistatic pressure inside the cabin required a longer time to reach the peak. The peak pressure of the formula $2 \mathrm{ex}-$ plosive was significantly higher than that of the formula 1 explosive because the peak value of the quasistatic pressure depends not only on the anaerobic reaction phase of the

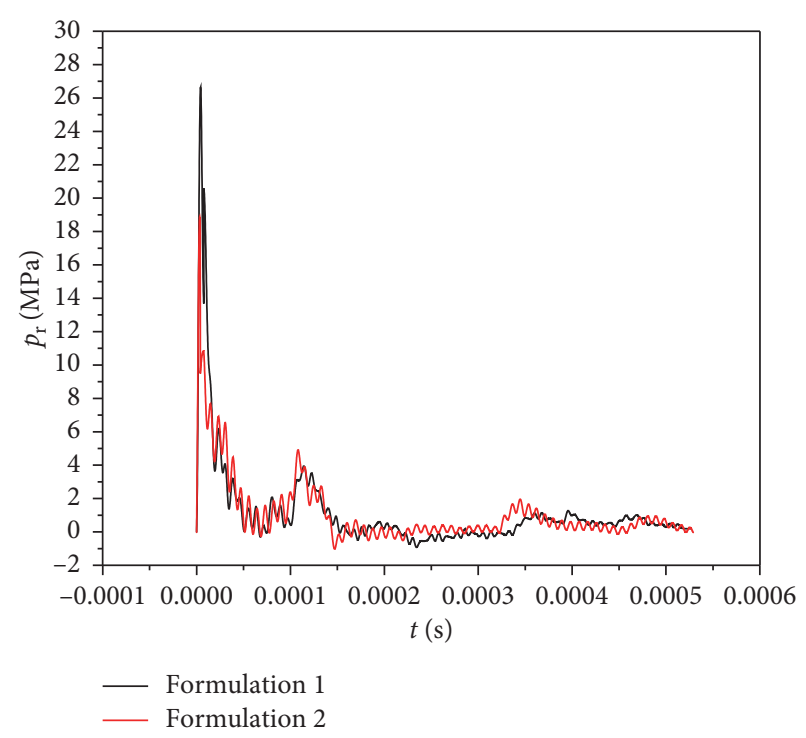

Figure 5: Pressure-time curve of the first incident shock wave.

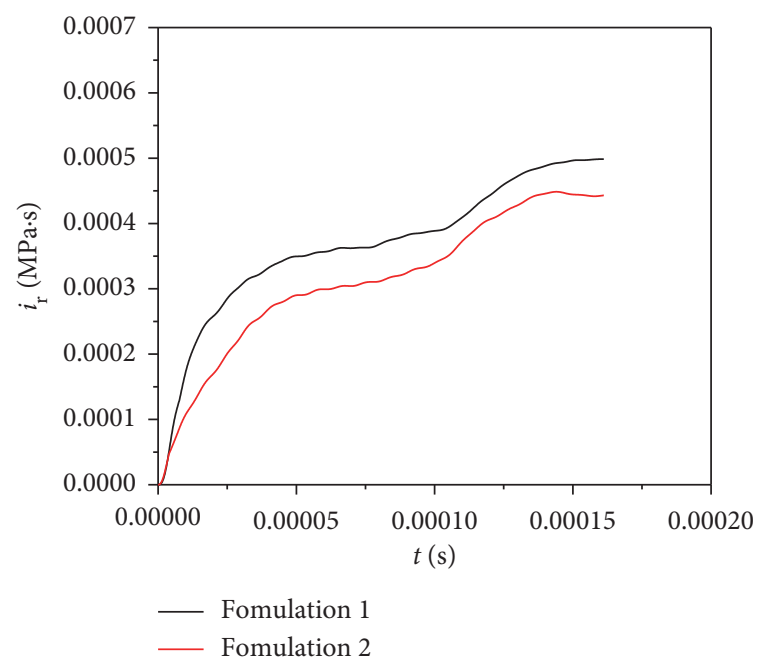

Figure 6: Impulse-time curve of the first incident shock wave.

explosive but also on the energy released during the postaerobic combustion phase. With a strong aerobic postcombustion effect, the aluminum-containing explosive released more energy than the ideal explosive. For example, given the same mass, the aluminum-containing explosive produced a greater quasistatic pressure than the ideal explosive. In the case where the area of pressure released by the cabin was the same, the pressure relief time of the formula 2 explosive was slightly longer than that of the formula 1 explosive because the quasistatic pressure of the aluminumcontaining explosive had a larger overpressure. Furthermore, there was a small difference between the two working conditions in terms of pressure relief time, which indicated that the area of pressure relief had a greater influence on the pressure relief time of the quasistatic time than the peak overpressure. The impulse-time curve of the quasistatic pressure has been obtained by integral calculation from the curve in Figure 7, as shown in Figure 8. 


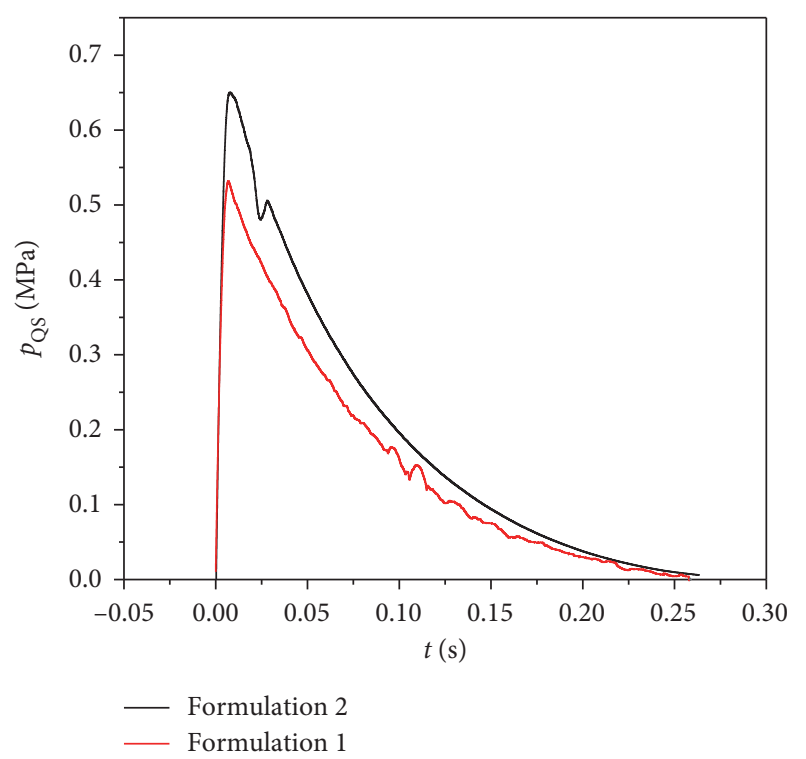

Figure 7: Pressure-time curve of the quasistatic pressure.

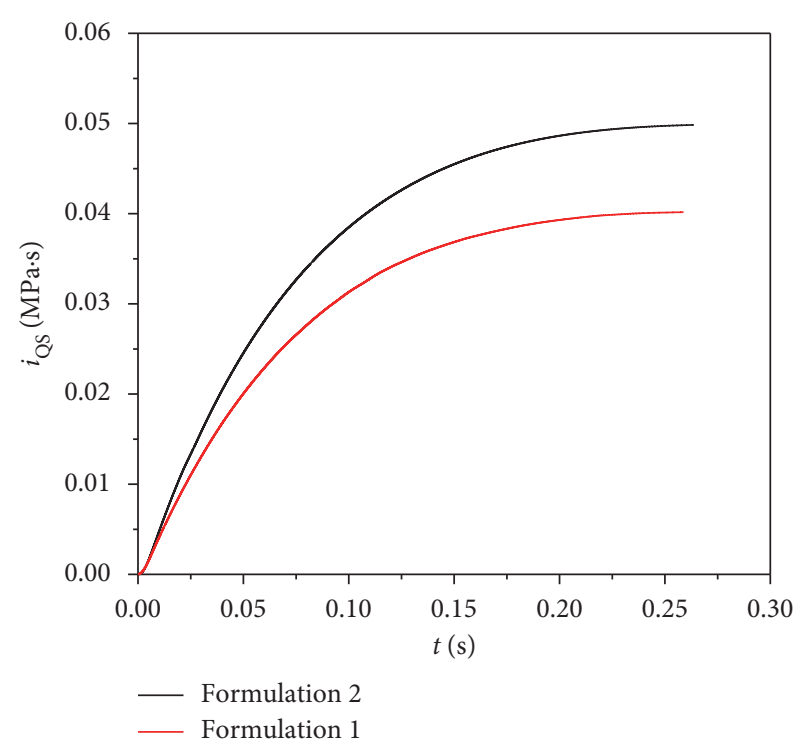

FIgURE 8: Impulse-time curve of the quasistatic pressure.

For the aluminum-containing explosive, its internal explosion pressure load characteristics were characterized by a first incident shock wave with a high peak value but short duration and a quasistatic pressure with a low peak value but long duration; this was similar to the pressure load characteristics of the ideal explosive. Compared with ideal explosives, the aluminum-containing explosive had a lower peak overpressure of the first incident shock wave and a shorter positive pressure action time; however, it had a higher peak overpressure of quasistatic pressure and a longer positive pressure action time.

4.1. Analysis of Pressure Load Parameters. To study the internal explosion pressure load parameters of aluminum-containing explosives, the experimental values were compared with the calculated values. The peak overpressures of the two pressure loads were the main parameters examined.

4.1.1. First Incident Shock Wave. To calculate the reflected shock wave pressure, the incident shock wave pressure should be calculated first. The incident pressure was obtained by using the equation proposed by $\mathrm{Wu}$ and Hao [36]:

$$
\begin{aligned}
& p_{\mathrm{s}}= \begin{cases}\frac{1.059}{\bar{R}^{2.56}}-0.51, & 0.1 \leq \bar{R} \leq 1, \\
\frac{1.008}{\bar{R}^{2.01}}, & 1<\bar{R} \leq 10,\end{cases} \\
& \bar{R}=\frac{R}{\sqrt[3]{m}},
\end{aligned}
$$

where $p_{\mathrm{s}}$ is the peak overpressure of the incident shock wave $(\mathrm{MPa}), \bar{R}$ is the proportional distance $\left(\mathrm{m} / \mathrm{kg}^{1 / 3}\right), R$ is the distance from the shock wave to the center of the explosion $(\mathrm{m})$, and $m$ is the TNT equivalent $(\mathrm{kg})$.

In the experiment, the two points to test the shock wave were located where the shock wave is normally reflected. Some studies have been conducted on the calculation of the first normally reflected shock wave pressure, which is usually calculated based on the incident shock wave. In this study, the equation proposed by Newsmark [37], with a relatively large range of application, was selected to calculate the overpressure of the normal reflected shock wave:

$$
p_{\mathrm{r}}=2 p_{\mathrm{S}}\left(1.5+4 \log _{10} p_{\mathrm{S}}\right),
$$

where $p_{s}$ is the peak overpressure of the incident shock wave $(\mathrm{MPa})$ and $p_{\mathrm{r}}$ is the peak overpressure of the reflected shock wave (MPa) (Table 2).

Comparision of experimental and calculated values in Table 3 is performed based on the theoretical values in Table 2. As shown in Table 3, there was a small error between the experimental value and theoretical value of the peak overpressure of the first incident shock wave of the nonaluminum-containing explosive. However, this error was quite large for the aluminum-containing explosive. The classical method of calculating the load parameters of the shock wave caused by an explosion usually involves two parameters: the TNT equivalent of the explosive and the distance from the test point to the bombing point. The TNT equivalent of the explosive is calculated according to the explosion heat theory. The explosion heat value represents the total energy released by the explosive reaction per unit mass. As for nonaluminum-containing explosives, given the explosion heat value of the explosive, the load parameters of the shock wave of the explosive can accurately be determined. Since the aluminum-containing explosive had a strong postcombustion reaction, under the circumstance of the same benchmark explosive, the explosion heat value of the aluminum-containing explosive was larger than that of the nonaluminum-containing explosive. However, the energy released by the postcombustion reaction of the aluminum powder did not act on the 
TABLE 2: Peak pressure of the first incident shock wave.

\begin{tabular}{lccc}
\hline Formula & Mass $(\mathrm{g})$ & TNT equivalent $(\mathrm{g})$ & Overpressure $(\mathrm{MPa})$ \\
\hline 1 & 40 & 52 & 1.80 \\
2 & 40 & 70 & 2.33 \\
\hline
\end{tabular}

TAвLE 3: Comparison of experimental and calculated values of the first incident shock wave peak pressure.

\begin{tabular}{lccc}
\hline Formula & Experimental value $(\mathrm{MPa})$ & Calculated value $(\mathrm{MPa})$ & Relative error $(\%)$ \\
\hline 1 & 26.65 & 26.13 & 1.99 \\
2 & 19.23 & 34.97 & -45.01 \\
\hline
\end{tabular}

TABLE 4: Comparison of experimental and calculated values of quasistatic peak pressure.

\begin{tabular}{lccc}
\hline Formula & Experimental value $(\mathrm{MPa})$ & Calculated value $(\mathrm{MPa})$ & Relative error $(\%)$ \\
\hline 1 & 0.530 & 0.532 & -0.38 \\
2 & 0.650 & 0.671 & -3.13 \\
\hline
\end{tabular}

detonation wave front. Thus, the explosion shock wave load parameters of the aluminum-containing explosive calculated using the explosion heat theory turned out to be higher than the measured values.

4.1.2. Quasistatic Pressure. The peak overpressure of the quasistatic pressure is determined by the total energy released by the explosion and the volume of the cabin. In this study, the equation proposed by Anderson et al. [23] was used to calculate the peak overpressure of the quasistatic pressure:

$$
\begin{array}{ll}
\bar{p}= \begin{cases}1.336\left(\frac{W}{p_{0} V}\right)^{0.6717}, & 0<\frac{W}{p_{0} V} \leq 350, \\
0.1388 \frac{W}{p_{0} V}, & \frac{W}{p_{0} V}>700,\end{cases} \\
\bar{p}=\frac{p_{\mathrm{QS}}+p_{0}}{p_{0}},
\end{array}
$$

where $V$ is the volume of the cabin $\left(\mathrm{m}^{3}\right), W$ is the total energy released by the explosion $(J), p_{0}$ is the standard atmospheric pressure $(\mathrm{MPa})$, and $p_{\mathrm{QS}}$ is the peak overpressure of the quasistatic pressure $(\mathrm{MPa})$.

As shown in Table 4, there was a small relative error between the experimental value and the theoretical value of the peak overpressure of the quasistatic pressure. According to the load characteristics and formation mechanism of the quasistatic pressure, the load parameters of the quasistatic pressure were directly correlated with the total energy released by the explosion of the explosive but were not related to the reaction process. Hence, the aerobic postcombustion reaction of the aluminum-containing explosive does not affect the analysis and calculation of the load parameters of the quasistatic pressure. Therefore, if the explosion heat value of the explosive is known, the load parameters of the quasistatic pressure can be accurately obtained.

\section{Conclusion}

To analyze the characteristics of the first incident shock wave and the quasistatic pressure formed by the explosion of a charge in a cabin, an internal explosion experiment was carried out in a simulation cabin in this study. Effective experimental data were obtained and compared with the values from the classical calculation model. According to the comparison, the following conclusions were drawn:

(1) Given the same mass and benchmark explosive, the pressure loads generated by the ideal explosive and the aluminum-containing explosive in the enclosed cabin have the same characteristics. The difference between the two explosives mainly lies in the amplitude of the load parameters. The first incident shock wave of the ideal explosive is higher than that of the aluminum-containing explosive; however, the quasistatic pressure of the ideal explosive is lower than that of the aluminum-containing explosive.

(2) For the peak overpressure of the first incident shock wave, since the aluminum-containing explosive has a strong postcombustion reaction, given the same benchmark explosive, the explosion heat value of the aluminum-containing explosive is higher than that of the nonaluminum-containing explosive. Therefore, the peak overpressure of the shock wave of the aluminumcontaining explosive calculated based on the explosion heat theory is higher than the measured value. The peak quasistatic overpressure is directly related to the total energy released by the explosion, but they are hardly related to the reaction process. Therefore, the aerobic postcombustion reaction of the aluminum-containing explosive will not affect the analysis and calculation of the peak quasistatic overpressure. In other words, given the heat value of the explosive, the peak quasistatic overpressure of the explosive can accurately be obtained. 


\section{Data Availability}

The datasets supporting the conclusions of this article are available from the corresponding authors upon request.

\section{Conflicts of Interest}

The authors declare that they have no conflicts of interest.

\section{Acknowledgments}

This work was supported by the National Program on Key Basic Research Project of China (613305).

\section{References}

[1] M. Dorn, M. Nash, G. Anderson, N. Jones, and C. A. Brebbia, "The numerical prediction of the collapse of a complex brick building due to an internal explosion," Pressure Vessels \& Piping Division, vol. 351, pp. 349-358, 1996.

[2] B. M. Luccioni, R. D. Ambrosini, and R. F. Danesi, "Failure of a reinforced concrete building under blast loads," WIT Transactions on Engineering Sciences, vol. 49, pp. 336-345, 2006.

[3] W. S. Filler, "Post-detonation pressure and thermal studies of solid high explosives in a closed chamber," Symposium (International) on Combustion, vol. 6, no. 1, pp. 648-657, 1957.

[4] W. E. Baker, P. A. Cox, P. S. Westine, J. J. Kulesz, and R. A. Strehlow, Explosion Hazards and Evaluation, Elsevier, Amsterdam, Netherlands, 1983.

[5] G. F. Kinney, Explosive Shocks in Air, Macmillan, New York, NY, USA, 1962.

[6] M. Y. H. Bangash, Impact and Explosion. Analysis and Design, Spon Press: Blackwell Scientific Publications, Oxford, UK, 1993.

[7] M. Michael and Swisdak Jr., "Explosion effects in air," Final Report A445810, 1975.

[8] R. E. Shear and R. C. Makino, "A non-linear shock wave reflection theory," Pentagon Report Number: 0549946, 1967.

[9] W. A. Keenan and J. E. Tancreto, Blast Environmental for Fully and Partially Vented Explosion in Cubicles, Civil Engineering Laboratory, Dover, NJ, USA, 1975.

[10] C. N. Kingery, R. N. Schumacher, and W. Ewing Jr., Internal Pressure from Explosions in Suppressive Structures, Ballistic Research Laboratory, Aberdeen, WA, USA, ADA019026, 1978.

[11] UFC 3-340-02 (Unified Facilities Criteria), Structures to Resist the Effects of Accidental Explosions, Dept. of the Army, The Navy and the Air Force, Washington, DC, USA, 2008.

[12] TM-5-855-1, Fundamentals of Protective Design for Conventional Weapons, Department of Army, Washington, DC, USA, 1986.

[13] AASTP-1, Manual of NATO Safety Principles for the Storage of Military Ammunition and Explosives, NATO International Staff-Defense Investment Division, Brussels, Belgium, 2006.

[14] W. E. Baker, "Prediction and scaling of reflected impulse from strong blast waves," International Journal of Mechanical Sciences, vol. 9, no. 1, pp. 45-51, 1967.

[15] J. M. K. Chock and R. K. Kapania, "Review of two methods for calculating explosive air blast," The Shock and Vibration Digest, vol. 33, no. 2, pp. 91-102, 2001.

[16] F. Rigas and S. Sklavounos, "Experimentally validated 3-D simulation of shock waves generated by dense explosives in confined complex geometries," Journal of Hazardous Materials, vol. 121, no. 1-3, pp. 23-30, 2005.

[17] C. D. Eamon, "Reliability of concrete masonry unit walls subjected to explosive loads," Journal of Structural Engineering, vol. 133, no. 7, pp. 935-944, 2007.

[18] J. L. O'Daniel and T. Krauthammer, "Assessment of numerical simulation capabilities for medium-structure interaction systems under explosive loads," Computers and Structures, vol. 63, no. 5, pp. 875-887, 1997.

[19] S. Sklavounos and F. Rigas, "Computer-aided modeling of the protective effect of explosion relief vents in tunnel structures," Journal of Loss Prevention in the Process Industries, vol. 19, no. 6, pp. 621-629, 2006.

[20] J. Dragos, C. Wu, and D. J. Oehlers, "Simplification of fully confined blasts for structural response analysis," Engineering Structures, vol. 56, pp. 312-326, 2013.

[21] H. R. W. Weibull, "Pressures recorded in partially closed chambers at explosion of tnt charges," Annals of the New York Academy of Sciences, vol. 152, no. 1, pp. 357-361, 1968.

[22] J. F. Proctor and W. S. Filler, "A computerized technique for blast loads from confined explosions," in Proceedings of the Minutes of the Fourteenth Annual Explosions Safety Seminar, pp. 99-124, New Orleans, LA, USA, November 1972.

[23] C. E. Anderson, W. E. Baker, D. K. Wauters, and B. L. Morris, "Quasi-static pressure, duration, and impulse for explosions (e.g. HE) in structures," International Journal of Mechanical Sciences, vol. 25, no. 6, pp. 455-464, 1983.

[24] I. Edri, Z. Savir, V. R. Feldgun, Y. S. Karinski, and D. Z. Yankelevsky, "On blast pressure analysis due to a partially confined explosion: I. Experimental studies," International Journal of Protective Structures, vol. 2, no. 1, pp. 1-20, 2011.

[25] Z. Savir, I. Edri, V. R. Feldgun, Y. S. Karinski, and D. Z. Yankelevsky, "Blast pressure distribution on interior walls due to a partially confined explosion," in Proceedings of the International Workshop on Structure Response to Impact and Blast (IWSRIB), Haifa, Israel, November 2009.

[26] I. Edri, V. R. Feldgun, Y. S. Karinski, and D. Z. Yankelevsky, "On blast pressure analysis due to a partially confined explosion: III. Afterburning effect," International Journal of Protective Structures, vol. 3, no. 3, pp. 311-331, 2012.

[27] V. R. Feldgun, Y. S. Karinski, I. Edri, and D. Z. Yankelevsky, "Prediction of the quasi-static pressure in confined and partially confined explosions and its application to blast response simulation of flexible structures," International Journal of Impact Engineering, vol. 90, no. 15, pp. 46-60, 2016.

[28] C. Wu, M. Lukaszewicz, K. Schebella, and L. Antanovskii, "Experimental and numerical investigation of confined explosion in a blast chamber," Journal of Loss Prevention in the Process Industries, vol. 26, no. 4, pp. 737-750, 2013.

[29] Y. Hu, C. Wu, M. Lukaszewicz, J. Dragos, J. Ren, and M. Haskett, "Characteristics of confined blast loading in unvented structures," International Journal of Protective Structures, vol. 2, no. 1, pp. 21-43, 2011.

[30] M. Larcher, F. Casadei, and G. Solomos, "Influence of venting areas on the air blast pressure inside tubular structures like railway carriages," Journal of Hazardous Materials, vol. 183, no. 1-3, pp. 839-846, 2010.

[31] X. U. Wei-Zheng and W. U. Wei-Guo, "Effects of size of venting holes on the characteristics of quasi-static overpressure in confined space," Chinese Journal of High Pressure Physics, vol. 31, no. 5, pp. 619-628, 2017.

[32] W. Xu, W. Wu, and Y. Lin, "Numerical method and simplified analytical model for predicting the blast load in a partially 
confined chamber," Computers \& Mathematics with Applications, vol. 76, no. 2, pp. 284-314, 2018.

[33] W. A. Trzciński, S Cudziło, J Paszula, and J. Callaway, "Studies of the effect of particles size on non-ideal explosives performance," Propellants, Explosives, Pyrotechnics, vol. 33, no. 3, pp. 227-235, 2008.

[34] P.-G. Jin, W. Guo, J.-L. Wang et al., "Energy releasing characteristics of aluminum powder in HMX-based explosives," Chinese Journal of Energetic Matterials, vol. 23, no. 10, pp. 989-993, 2015.

[35] S. Y. Sui and S. S. Wang, Terminal Effect, National Defence Industry Press, Beijing, China, 2000.

[36] C. Wu and H. Hao, "Modeling of simultaneous ground shock and airblast pressure on nearby structures from surface explosions," International Journal of Impact Engineering, vol. 31, no. 6, pp. 699-717, 2005.

[37] N. M. Newmark, "External blast," in Proceedings of the International Conference on Planning and Design of Tall Buildings, pp. 76-661, Lehigh University: ASCE-IABSE, Bethlehem, Pennsylvania, August 1972. 


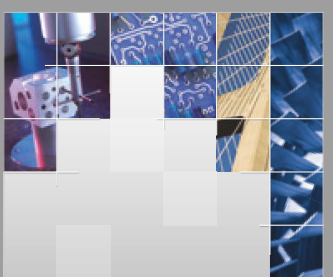

\section{Enfincering}
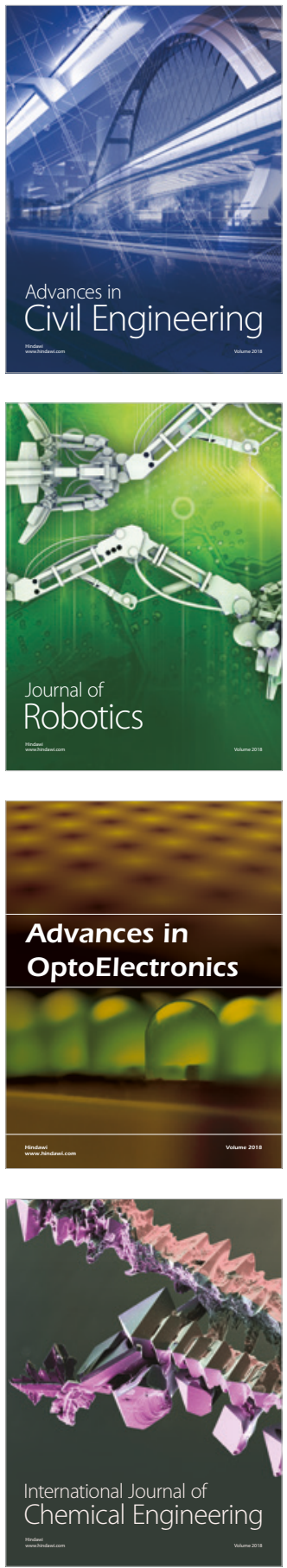

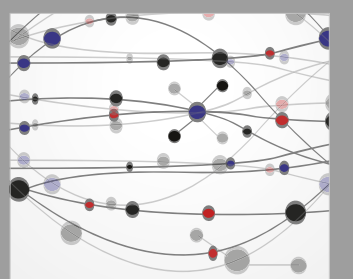

\section{Rotating \\ Machinery}

The Scientific World Journal

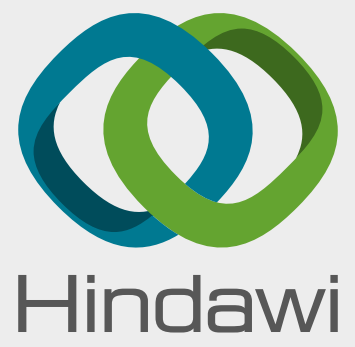

Submit your manuscripts at

www.hindawi.com
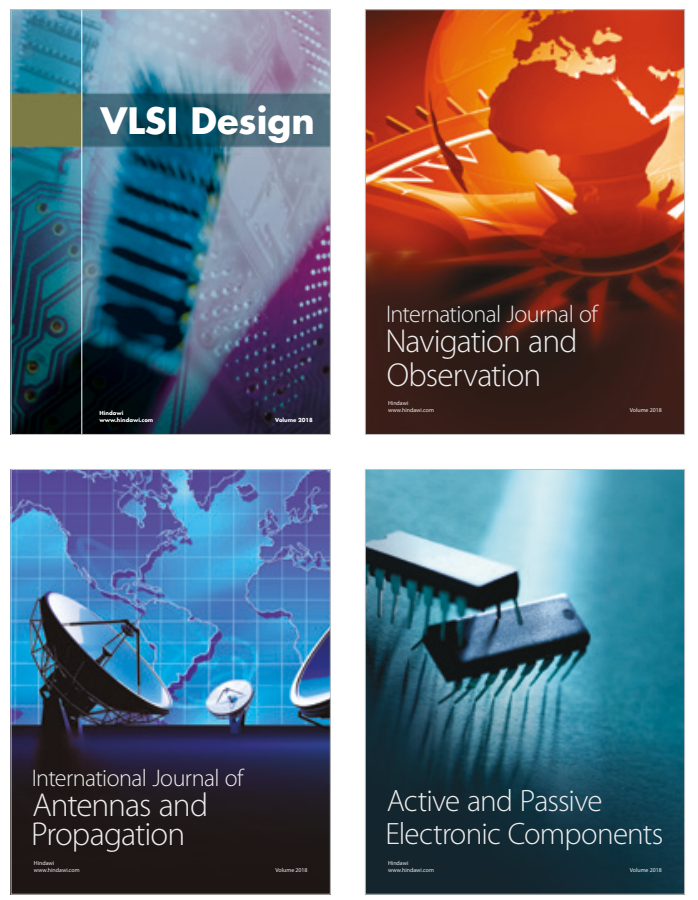
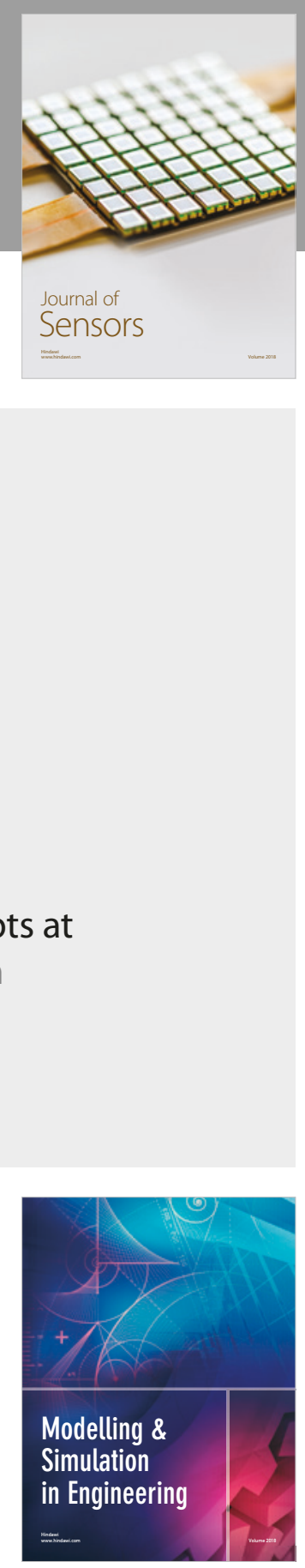

\section{Advances \\ Multimedia}
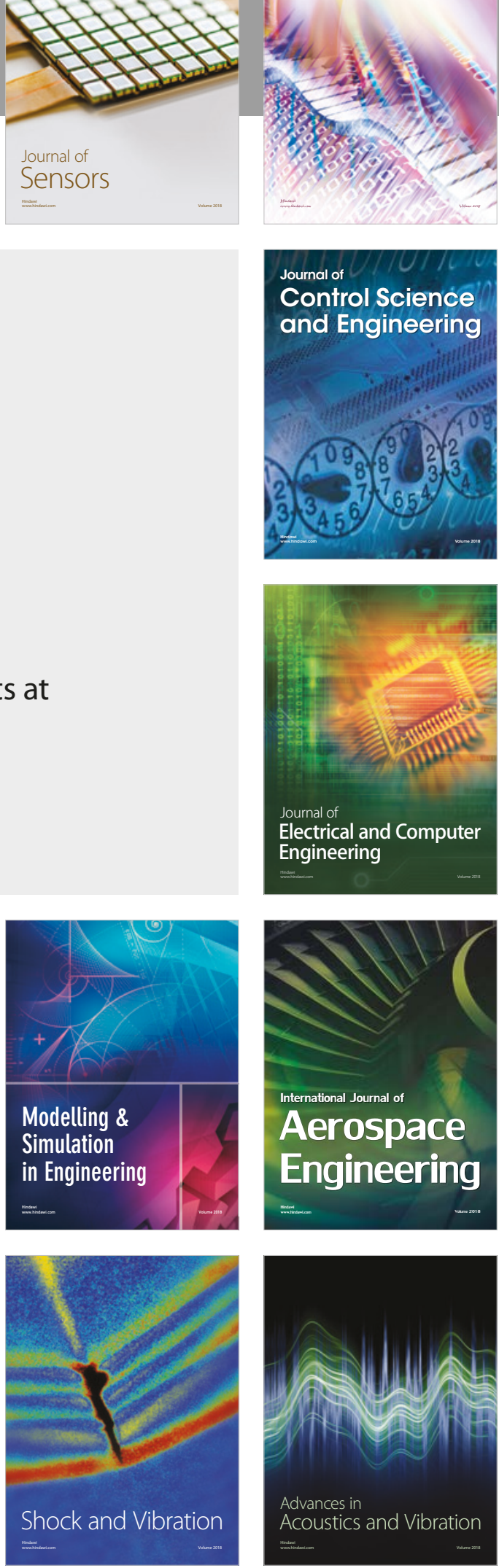